УДК 122/129

\title{
DOI 10.19181/2227-8656.2020.1.5
}

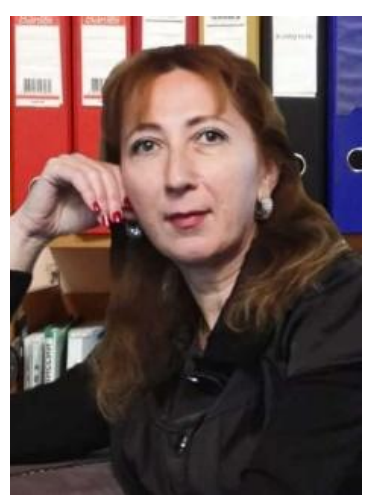

МЕДИАЦИЯ

КАК АЛЬТЕРНАТИВНАЯ ПРОЦЕДУРА

КОНФЛИКТОРАЗРЕШЕНИЯ

В СОВРЕМЕННОМ РОССИЙСКОМ ОБЩЕСТВЕ

\author{
Агапова Елена Анатольевна \\ Доктор философских наук, доцент, \\ заведующая кафедрой \\ социальной философии, \\ Институт философии \\ и социально-политических наук, \\ Южный федеральный университет, \\ г. Ростов-на-Дону, Россия, \\ e-mail: eagapova@sfedu.ru
}

\section{Дюжиков Сергей Александрович}

Доктор философских наук, профессор,

заведующий кафедрой прикладной

конфликтологии и медиации,

Институт социологии и регионоведения,

Южный федеральный университет,

г. Ростов-на-Дону, Россия,

e-mail:duzhikov@sfedu.ru

В статье осуществлен трансдисциплинарный анализ медиации как альтернативной процедуры конфликторазрешения в условиях реалий современного российского общества. Проведенный в статье краткий

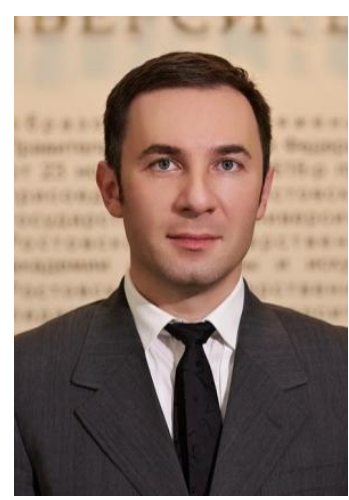

MEDIATION

AS AN ALTERNATIVE CONFLICT RESOLUTION PROCEDURE IN MODERN RUSSIAN SOCIETY

Elena A. Agapova

Doctor of Philosophical Sciences,

Associate Professor, Head of the Department of Social Philosophy, Institute of Philosophy and Socio-political Sciences, Southern Federal University, Rostov-on-Don, Russia, e-mail: eagapova@sfedu.ru

\section{Sergey A. Dyuzhikov}

Doctor of Philosophical Sciences, Professor,

Head of the Department of Applied Conflictology and Mediation, Institute of Sociology and Regional Studies, Southern Federal University, Rostov-on-Don, Russia, e-mail: duzhikov@sfedu.ru

The article provides a transdisciplinary analysis of mediation as an alternative conflict resolution procedure under the realities of modern Russian society. The brief review of modern scientific research conducted in the 
обзор современных научных исследований позволил провести сравнительный анализ различных способов конфликторазрешения, рассмотреть причины большей общественной популярности разрешения споров через систему государственного принуждения и меньшей популярности в настоящее время альтернативной процедуры медиации. При этом анализируется появившаяся новая альтернативная процедура - привлечение судебного примирителя к разрешению спора. Показано, что участие судебного примирителя в разрешении конфликта есть новое в праве, а следовательно, и в социокультурной системе российского общества.

Ключевые слова: конфликт; конфликторазрешение; российское общество; посредничество; медиация; судебные примирители; ментальность; социокультурная система. article allowed us to make a comparative analysis between different methods of conflict resolution, to consider the reasons for the greater public popularity of dispute resolution through the system of state coercion and the less popular alternative procedure - mediation. At the same time, we analyze the new alternative procedure - involving a judicial conciliator in the resolution of a dispute. It is shown that the participation of a judicial conciliator in conflict resolution is new in law, and, consequently, in the sociocultural system of Russian society.

Keywords: conflict; conflict resolution; Russian society; mediation; judicial conciliators; mentality; socio-cultural system.

\section{Введение}

Целью данной публикации является научно-практическое изучение особенностей разрешения конфликтов в современном российском обществе. Сложившаяся система судебного решения споров хорошо прижилась в общественном сознании. Известно, что судебная система перегружена подаваемыми исками. Аналогичная ситуация и в процедуре административного обжалования. Граждане активно обращаются в органы власти с требованиями справедливости, вовлечения государственного аппарата в разрешение конфликта, наказания обидчиков: должностных лиц, учреждений, организаций, предприятий, нарушающих права, свободы и законные интересы. Обе эти процедуры хорошо отработаны, популярны, но все чаще мы слышим, что они излишне бюрократизированы, малоэффективны, затянуты по времени, затратны финансово, не оставляют чувства справедливого решения спора, удовлетворяющего стороны.

Популярность этих процедур можно связать с российской ментальностью, со сложившейся традицией перекладывать ответственность на государство, третьих лиц, имеющих власть, специальные полномочия, а не прибегать к возможности договориться. Но государственный аппарат стремится вынести из зала суда и кабинетов начальников рассмотрение спорных ситуаций, так как для государства не 
представляется рентабельным постоянное расширение штата служащих. Поэтому в 2010 г. была предложена альтернативная процедура разрешения спора - процедура медиации, которая является популярной в странах Западной Европы и США.

Актуальность данной проблемы в настоящий момент связана с тем, что через 9 лет применения этой процедуры законодатель вводит еще одну альтернативную процедуру урегулирования конфликта процедуру привлечения судебного примирителя. Необходимо понять, в чем необходимость в такой процедуре сейчас? Государственному аппарату все сложнее решать споры? Или все-таки альтернативные процедуры хорошо себя зарекомендовали?

Принятые в 2019 - начале 2020 г. изменения и дополнения нормативно-правовых актов предопределяют необходимость изучения обоих способов урегулирования конфликта, их сопоставления и выявления преимуществ и недостатков. Полученные результаты исследования могут быть использованы при преподавании дисциплин по медиации и конфликтологии, в гражданском и административном процессе, в рамках научных конференций, рассмотрены как междисциплинарная проблема для юристов, конфликтологов, социологов и т. д.

Актуальность данного исследования определяется также растущим интересом к возможности применения альтернативных процедур урегулирования конфликтов, и появившаяся новая возможность, несомненно, откроет дополнительные перспективы для переноса рассмотрения споров из зала суда на другие площадки. Но как сторонам разобраться, какая процедура больше применима к их ситуации? Анализ преимуществ и недостатков приводится в данном исследовании. Можно сказать, что исследование двух процедур и сделанные выводы позволят облегчить выбор конфликтующим сторонам в подборе посредника в урегулировании конфликта.

\section{Судебные примирители - посредники урегулирования конфликтов}

Федеральный конституционный закон от 26.07.2019 № 3-ФКЗ «О внесении изменений в статью 5 Федерального конституционного закона “О Верховном Суде Российской Федерации" в связи с совершенствованием примирительных процедур», Федеральные законы от 26.07.2019 № 197-Ф3 «О внесении изменений в отдельные законодательные акты Российской Федерации» и № 198-ФЗ «О внесении изменений в статью 333-40 части второй Налогового кодекса Российской Федерации в связи с совершенствованием примирительных процедур» существенно расширили возможности применения процедур альтернативного (внесудебного) 
урегулирования споров с помощью судебных примирителей. В развитие данных законов было принято постановление Пленума Верховного суда Российской Федерации от 31.10.2019 № 41, которое утвердило регламент проведения судебного примирения. Данные нормативно-правовые акты были приняты с целью реализации положений Конституции Российской Федерации, которая в статье 45 указывает на право каждого «защищать свои права и свободы всеми способами, не запрещенными законом», а также расширения возможностей внесудебного рассмотрения споров, которые были предусмотрены Федеральным законом от 27.07.2010 № 193Ф3 «Об альтернативной процедуре урегулирования споров с участием посредника (процедуре медиации)».

Девять лет в России действует процедура медиации. За это время сформирована система ее применения: созданы образовательные программы подготовки медиаторов; функционируют общественные объединения медиаторов, собирающие информацию, готовящие аналитику, дающие рекомендации, ведущие базу данных и т. д.; данная процедура широко популяризируется среди конфликтующих сторон; научное сообщество проводит исследования эффективности применения данной процедуры (Шеянов, 2016; Дюжиков, 2019; Гугуева, 2018). Несмотря на это, процент применения медиации остается достаточно низким. Но у профессионального сообщества вера в большие перспективы процедуры медиации, конечно, остается.

В это время законодатель вводит дополнительную возможность разрешить конфликт - использовать судебного примирителя в качестве посредника. Встает вопрос: в чем разница, какие преимущества?

В обеих процедурах есть много общего и есть существенные отличия. Исходя из положений Федерального закона «Об альтернативной процедуре урегулирования споров с участием посредника (процедуре медиации)», процедура медиации - это «способ урегулирования споров при содействии медиатора на основе добровольного согласия сторон в целях достижения ими взаимоприемлемого решения». При этом указывается, что целью применения данной процедуры является содействие «развитию партнерских деловых отношений и формированию этики делового оборота, гармонизации социальных отношений». И данная процедура применима «к спорам, возникающим из гражданских правоотношений, в том числе в связи с осуществлением предпринимательской и иной экономической деятельности, а также спорам, возникающим из трудовых правоотношений и семейных правоотношений». Утверждение в законе, что «процедура медиации может применяться после возникновения споров, рассматриваемых в порядке гражданского судопроизводства и судопроиз- 
водства в арбитражных судах», не ограничивает ее использование без намерения прибегнуть к судебному решению конфликта.

В соответствии с регламентом проведения судебного примирения судебное примирение является примирительной процедурой, используемой для таких задач судопроизводства, как мирное урегулирование споров, содействие становлению и развитию партнерских деловых отношений, формированию обычаев и этики делового оборота, которое может проводиться на любой стадии судебного процесса и при исполнении судебного акта, если нет прямого противоречия кодексам и федеральным законам.

Таким образом, можно сделать вывод, что, несмотря на общие цели и задачи обеих процедур, существенным отличием является широта спектра применения медиации в трудовых, семейных, экономических и иных спорах, так как позволяет исключить саму необходимость обращения в суд.

Другой важный аспект - финансирование процедуры. В соответствии с законом медиация может проводится как на платной, так и на бесплатной основе, в то время как в регламенте четко указывается, что сторонами процедура не оплачивается. Это делает процедуру судебного примирения более финансово привлекательной, что, конечно, может ударить по спросу на оказание услуг медиаторов. Здесь, безусловно, придется включать различные рыночные элементы увеличения спроса на данную услугу, что также неплохо для потребителя услуги. Конкуренция может повысить качество и снизить стоимость услуги.

Разница процедур очевидна при регламентации требований, предъявляемых к примирителям и медиаторам. В соответствии с регламентом судебным примирителем является судья, пребывающий в отставке и включенный в список судебных примирителей, который утверждается Пленумом Верховного суда Российской Федерации. В регламенте уделено значительное внимание требованиям к судебным примирителям. В п. 2 ст. 9 регламента указывается, что при формировании списка учитываются в том числе опыт работы в качестве судьи, опыт научной деятельности, специализация, регион проживания кандидата, деятельность, осуществляемая судьей с момента ухода в отставку, и соответствие данной деятельности законодательству о статусе судей и кодексу судейской этики. Таким образом, формирование состава судебных примирителей предполагает юридическое образование, стаж работы в качестве судьи и иные вышеперечисленные требования.

В то же время требования к медиаторам менее жесткие. Законодательно определено, что деятельность медиатора может осуществляться 
как на профессиональной, так и на непрофессиональной основе. Осуществлять деятельность медиатора на непрофессиональной основе могут лица, достигшие возраста 18 лет, обладающие полной дееспособностью и не имеющие судимости. А быть медиаторами на профессиональной основе могут лица, достигшие возраста 25 лет, имеющие высшее образование и получившие дополнительное профессиональное образование по вопросам применения процедуры медиации (Максуров, 2014). Есть и ограничение: медиаторами не могут быть лица, замещающие государственные должности Российской Федерации, государственные должности субъектов Российской Федерации, должности государственной гражданской службы, должности муниципальной службы, если иное не предусмотрено федеральными законами. То есть законодательно не установлена конкретная образовательная специализация (диплом о высшем образовании, только дополнительное профильное образование для профессиональных медиаторов); опыт работы может быть минимальным, требований к нему нет.

В каждом случае есть свои преимущества и недостатки. Нам представляется, что предложенные требования для медиаторов дают большую свободу выбора для участников урегулирования конфликта. Юридическое образование и многолетний судебный опыт могут помочь решить спорную ситуацию более квалифицированно с юридической точки зрения, но вряд ли максимально оптимально для конфликтующих сторон. Подготовка медиаторов традиционно носит междисциплинарный характер. Она включает право, психологию, конфликтологию, социологию и другие дисциплины. Исходя из целей и задач процедур по определению взаимовыгодных условий разрешения спора, устранению причин возникновения конфликта, нужны знания не только по юриспруденции, а скорее по психологии и другим дисциплинам, которые помогут самим сторонам конфликта найти условия примирения и налаживания партнерских отношений, как это закреплено законодательно.

Одним из преимуществ медиации всегда является имиджевая репутация сторон. Перенос рассмотрения дела из суда в более психологически комфортные условия является большим плюсом для медиации. Судебные обжалования существенно подрывают авторитет физических лиц, организаций, предприятий, учреждений. Рассмотрение конфликта через проведение процедуры медиации избавляет от этих репутационных рисков.

В данном исследовании приведены лишь некоторые примеры сопоставления двух процедур примирения - поиска взаимовыгодного решения спорной ситуации. Практика применения процедуры разрешения конфликта с помощью судебного примирения позволит изучить и иные особенности этих процедур. 


\section{Заключение}

Законодателем предложена еще одна форма урегулирования конфликта. Цель законодателя - совершенствование механизмов урегулирования споров и возможность разгрузить суды - всем понятна. Государственный аппарат пытается привить россиянам самостоятельность и чувство ответственности за принимаемые решения, научить формулировать решения и строго выполнять их. Сегодня можно увидеть, что медленно, но мы движемся к этой цели. Если бы идеи, заложенные при внедрении процедуры медиации, не оправдали себя, законодатель не стал бы расширять спектр альтернативных процедур. Можно с уверенностью сказать, что почти за 10 лет своей практики медиация доказала свою эффективность и внесла вклад в развитие современной российской системы защиты прав и законных интересов человека.

Теперь нам предстоит анализировать реализацию института судебных примирителей. Постановлением Пленума Верховного суда Российской Федерации от 28.01.2020 № 1 «Об утверждении списка судебных примирителей» уже назначены судебные примирители. Государственный аппарат сейчас начнет активно вовлекать физических и юридических лиц в процесс привлечения судебного примирителя к разрешению споров. Не до конца сформированный рынок услуг внесудебного разрешения конфликта с участием медиатора начнет делиться. Это может привести к улучшению качества услуг и снижению стоимости, большей активности медиаторов, так как созданный фундамент не даст системе распасться. Хочется выразить уверенность, что, несмотря на принимаемые законодателем меры по переориентации конфликтующих сторон на альтернативную процедуру урегулирования конфликта, но подконтрольную государству (нормативное, кадровое, финансовое обеспечение судебных примирителей), разрешение споров с привлечением медиатора имеет большие перспективы развития благодаря своим качественным преимуществам.

\section{Литература}

Гугуева Д.А., Еремина А.С. Медиация в образовательной среде // Обзор НЦПТИ. 2018. № 1 (12). С. $80-85$.

Дюжиков С.А., Нор-Аревян О.А. Проблемы и перспективы применения медиации в современных управленческих практиках // Социально-гуманитарные знания. 2019. № 7. C. $18-25$.

\section{References}

Gugueva, D.A., Eremina, A.S. (2018). Mediation in the educational environment. Obzor NCPTI, 1 (12), 80-85. (in Russian).

Duzhikov, S.A., Nor-Arevyan, O.A. (2019). Problems and prospects of mediation application in modern management practices. Social'no-gumanitarnye znaniya, $7,18-25$. (in Russian). 
Конституция РФ // Собрание законодательства РФ. 2014. № 31. Ст. 4398.

Максуров А.А., Таланова М.В. Медиация в праве: юридическая технология медиативных процедур. М.: ЭкООнис, 2014. $456 \mathrm{c}$.

Нор-Аревян О.A. Социальный капитал профессии в оценках российских врачей (на материалах социологического исследования в городских мегаполисах) // Власть. 2018. Т. 26, № 1. С. 98-107.

Федеральный закон от 27.07.2010 № 193-Ф3 «Об альтернативной процедуре урегулирования споров с участием посредника (процедуре медиации)» // Российская газета. 2010. № 168. 30 июля.

Федеральный конституционный закон от 26.07.2019 № 3-ФК3 «О внесении изменений в статью 5 Федерального конституционного закона "О Верховном суде Российской Федерации” в связи с совершенствованием примирительных процедур» // Российская газета. 2019. № 166. 31 июля.

Федеральный закон от 26.07.2019 № 197-Ф3 «О внесении изменений в отдельные законодательные акты Российской Федерации» // Российская газета. 2019. № 166. 31 июля.

Федеральный закон от 26.07.2019 № 198-Ф3 «О внесении изменений в статью 333-40 части второй Налогового кодекса Российской Федерации в связи с совершенствованием примирительных процедур» // Российская газета. 2019. № 166. 31 июля.

Шеянов В.Г., Велькина М.В. Преимущества медиации // Отечественная юриспруденция. 2016. № 5 (7).
The Constitution of the Russian Federation (2014). Collection of legislation of the Russian Federation, 31, art. 4398. (in Russian).

Maksurov, A.A., Talanova, M.V. (2014). Mediation in law: legal technology of mediation procedures. M.: EkOOnis. (in Russian).

Nor-Arevyan, O.A. (2018). Social capital of the profession in the assessments of Russian doctors (based on the materials of sociological research in urban megalopolises). Vlast', 26, 1, 98-107. (in Russian).

Federal law of 27.07.2010 No 193-FZ "On alternative dispute settlement procedure with the participation of a mediator (mediation procedure)" (2010). Rossiyskaya Gazeta, 168, July 30. (in Russian).

Federal constitutional law of 26.07.2019 No. 3 "On amendments to article 5 of the Federal constitutional law 'On the Supreme court of the Russian Federation' in connection with the improvement of conciliation procedures" (2019). Rossiyskaya Gazeta, 166, July 31. (in Russian).

Federal law No. 197 of 26.07.2019 "On amendments to certain legislative acts of the Russian Federation" (2019). Rossiyskaya Gazeta, 166, July 31. (in Russian).

Federal law of 26.07.2019 No. 198 “On amendments to article 333-40 of part two of the Tax code of the Russian Federation in connection with the improvement of conciliation procedures" (2019). Rossiyskaya Gazeta, 166, July 31. (in Russian).

Sheyanov, V.G., Velkina, M.V. (2016). Advantages of mediation. Otechestvennaya yurisprudenciya, 5 (7). (in Russian). 